\title{
Investigation on Tool Wear Mechanism during Dry Cutting 304 Stainless Steel
}

Jianjian Chen, Yufeng Wang, Yan Zhang, Shubao Yang, Xingquan Zhang

AnHui Province Key Laboratory of Special Heavy Load Robot, 243032, Maanshan, China.

School of Mechanical Engineering, Anhui University of Technology, 243032, Maanshan, China. E-mail: 879368554@qq.com,799148167@qq.com,1064321757@qq.com, sbyang2007@sina.com, zhxq@ahut.edu.cn

With the determined parameters of cutting speed, feed rate and back cutting depth, cemented carbide tool was adopted to dry cut 304 stainless steel, exploring the tool wear failure mechanism and its effect on the surface quality of the workpiece under different cutting times. The morphology of the tool surface is observed by scanning electron microscopy, and the component of the tool is analyzed by energy dispersive spectroscopy. The three-dimensional microscopic shape of workpiece surface is observed by a three-dimensional shape analyzer and the surface roughness $\mathrm{Ra}$ was measured. The results indicate that during the process of 6-minute cutting, the abrasive wear and adhesion wear are occurred on the tool, the surface quality of the machined workpiece is good; during the process of 12-minute cutting, oxidation wear is appeared while the tool subjects abrasive wear and adhesion wear, and the surface quality of the machined workpiece become pool; during the process of 18-minute cutting, the tool is under the combined action of various wear mechanism. Because of the passivation of tool nose, the surface quality of the workpiece is deteriorated, and it can't meet the requirements of finish machining. In the process of dry cutting workpieces by cemented carbide tool, the tool suffers abrasive wear, adhesion wear and oxidation wear. The surface quality of the workpiece is declined due to the passivation of the tool nose.

Keywords: Cemented carbide, 304 Stainless steel, Wear mechanism, Dry cutting, Surface roughness

\section{Introduction}

304 stainless steel is a kind of alloy with austenitic structure, and its production accounts for $45 \% \sim 55 \%$ of the total production of stainless steel. It still can maintain good resistance to corrosion under high temperature conditions, and it is widely used in many key fields of national economy, such as nuclear power housings and various pipes on marine power plants [1]. However, because of the low thermal conductivity, high toughness and high tensile strength of 304 stainless steel, the process of cutting is accompanied with large cutting resistance, severe work hardening, high cutting temperature and difficulty in chip breaking. It easily leads to tool wear, and results in short tool life and low cutting efficiency, so it is considered as a typical material to be cut hardly [2].

In recent years, many investigations have been devoted to improve cutting performance of stainless steel. JANAINA, G. C [3] employed cemented carbide tool to cut stainless steels, the results revealed that the dominant wear mechanisms were abrasion and diffusion wear. KROLCZYK, G. M [4-6] investigated the effect of different cutting parameters on tool life in duplex stainless turning process, and the conclusion shown that tool life was longer without using the cooling lubricant and the tool coated with $\mathrm{Al}_{2} \mathrm{O}_{3}$ had stronger wear resistance. JOHANNES, K [7] adopted cemented carbide tool to cut the carbon steel, and the tool wear was ascribed to crater wear, flank wear and corner radius wear. KOLAR, P [8] carried out the cutting experiments to present that the flank wear influenced the cutting force acting on the worn tool more significantly than cutting tool geometry. ROSA, G. C [9] conducted experimental research on tool wear and wear mechanism during cutting of AISI 420C stainless steel, the results showed that the influence of both cutting speed and feed rate over tool life, and the oxidation wear mechanism was indicated. SAKETI, S [10] applied cemented carbide tools with different grain sizes to cut austenitic stainless steel, and pointed out that fine grain tools have good wear resistance. NESLUSAN, M [11] studied the influence of tool wear on surface integrity after turning of stainless steel, and determined that the density of carbides played a significant role in the resistance of the matrix against the structure transformations. The above papers are very useful to understand the tool wear characteristics under the condition of cooling lubricant, which also provide a reference for actual cutting process. Recently, dry cutting, served as an environmentally friendly cutting technology, was presented, which eliminated a series of problems caused by cooling lubricant during cutting process such as environmental pollution, health risk of workers and cost increase [12]. Therefore, the dry cutting has attracted more and more attention of manufactures and researchers. Through comparative experiments, ANSELMO, E. D 
[13] found that the dry cutting could produce a smoother surface with less power consumption than cutting with cooling lubricant. KROLCZYK, G. M [14] investigated the average surface roughness in the dry cutting of duplex stainless steel and revealed that dry machining resulted in a reduction in friction for lubricated surfaces. PATHIRANAGAMA, G. J [15] studied experimentally the tool wear in dry machining of aluminium alloys and proposed the optimization scheme. However, these investigations mainly focused on cutting parameters or workpiece surface quality in dry cutting conditions. The wear and failure mechanisms of tools during dry cutting process of stainless steel have not been involved in the existing researches.

In this paper, the cemented carbide tool was employed to dry cut 304 stainless steel, and a series of tests were carried out. The wear mechanism of cemented carbide tool under different cutting times was stu- died, and the influence of tool wear on the surface quality of the workpiece was observed. The investigations can provide a reference for the dry cutting of poor-thermal-conductivity materials cut by the cemented carbide tools.

\section{Cutting test}

\subsection{Workpiece materials and tool}

The rod of 304 Stainless steel was used in cutting test, and its geometrical size was $\varnothing 40 \times 300 \mathrm{~mm}$. Its main chemical composition and physical properties were shown in Tab 1 and 2, respectively.

Tab. 1 Chemical composition of 304 stainless steel (mass fraction, \%)

\begin{tabular}{cccccc}
\hline $\mathrm{Fe}$ & $\mathrm{Si}$ & $\mathrm{Cu}$ & $\mathrm{S}$ & $\mathrm{Ni}$ & $\mathrm{Cr}$ \\
\hline Balance & 0.96 & 1.23 & 1.56 & 7.57 & 18.62 \\
\hline
\end{tabular}

Tab. 2 Thermo-mechanical properties of 304 stainless steel

\begin{tabular}{ccccccccc}
\hline Property & $\begin{array}{c}\text { Den- } \\
\text { sity } /\left(\mathrm{kg} / \mathrm{m}^{3}\right)\end{array}$ & $\begin{array}{c}\text { Melting } \\
\text { tempera- } \\
\text { ture } /{ }^{\circ} \mathrm{C}\end{array}$ & $\begin{array}{c}\text { Tensile } \\
\text { stren- } \\
\text { gth } / \mathrm{MPa}\end{array}$ & $\begin{array}{c}\text { Yield } \\
\text { stren- } \\
\text { gth } \\
/ \mathrm{MPa}\end{array}$ & $\begin{array}{c}\text { Elastic } \\
\text { modu- } \\
\text { lus, } \\
\mathrm{E} / \mathrm{GPa}\end{array}$ & $\begin{array}{c}\text { Hard- } \\
\text { ness, } \\
\mathrm{HB}\end{array}$ & $\begin{array}{c}\text { Elonga- } \\
\text { tion } / \%\end{array}$ & $\begin{array}{c}\text { Thermal } \\
\text { conducti- } \\
\text { vity/ } \\
{[\mathrm{W} /(\mathrm{m} \cdot \mathrm{k})]}\end{array}$ \\
\hline $\begin{array}{c}\text { Specifica- } \\
\text { tion }\end{array}$ & 7930 & 1398 & 520 & 205 & 193 & 187 & 40 & 16.3 \\
\hline
\end{tabular}

The dimension of tool was $13 \times 13 \times 4.5 \mathrm{~mm}$, and both the tool cutting edge angle and minor cutting angle were $45^{\circ}$. It's rake angle $\gamma_{0}$ and relief angle $\alpha_{0}$ were $6^{\circ}$ and $4^{\circ}$, respectively. The tool nose radius was 0.5 $\mathrm{mm}$, the transition edge width was $0.2 \mathrm{~mm}$, and the chip flute width was $3.4 \mathrm{~mm}$, and it's physical and mechanical properties were shown in Tab. 3. The indexable tool was installed by the machine clamp screw into the groove of the shank.

Tab. 3 Thermo-mechanical properties of tool

\begin{tabular}{|c|c|c|c|c|c|c|}
\hline Property & $\begin{array}{l}\text { Density } \\
/\left(\mathrm{kg} / \mathrm{m}^{3}\right)\end{array}$ & $\begin{array}{l}\text { Flexure } \\
\text { stren- } \\
\text { gth/MP }\end{array}$ & $\begin{array}{l}\text { Hard- } \\
\text { ness, } \\
\text { HRA }\end{array}$ & $\begin{array}{l}\text { Impact tou- } \\
\text { ghness J/M }\end{array}$ & $\begin{array}{c}\text { Elastic modulus, } \\
\mathrm{E} / \mathrm{GPa}\end{array}$ & Ingredient \\
\hline Specification & $1450 \sim 1490$ & 1500 & 89 & 2.5 & 600 & $\mathrm{WC}+8 \% \mathrm{Co}$ \\
\hline
\end{tabular}

\subsection{Cutting test scheme}

The cutting tests were carried out on a $\mathrm{CNC}$ lathe of model CK400, as shown in Fig. 1(a), whose motor power was $5.5 \mathrm{KW}$, and the speed range of spindle was $50-2500 \mathrm{r} / \mathrm{min}$. The experimental cutting parameters were as follows: cutting speed $80 \mathrm{~m} / \mathrm{min}$, cutting depth $0.6 \mathrm{~mm}$ and feed rate $0.12 \mathrm{~mm} / \mathrm{r}$. One end of 304 stainless steel rod was fixed by three-jaw chuck, and the other was supported by the thimble to improve the rigidity of the process system. From Fig. 1(b), the indexable tool was used for cutting, and the four noses of tool were marked with number $0,1,2$ and 3, respectively, the No. 0 tool nose was not involved in the cutting. In order to verify the tool wear mechanism, the experiments on different tool noses with different cutting times were carried out. When the cutting tests were completed, the surface of the tool was washed with acetone and dried in air. The wear contour of the rake and the flank of the tool were observed by the scanning electron microscope (JSM$6490 \mathrm{LV}$ ), and the distribution of the elements on the tool surface was analyzed by the energy dispersive spectrometer. At the same time, the three-dimensional morphology of the workpiece surface was obtained by RETC-UP 3D topography instrument. The measurement path was defined by the post-processing software Gwyddion. The surface contour was extracted along the defined path, and the surface roughness $\mathrm{Ra}$, arithmetic mean deviation of the profile, was measured. 


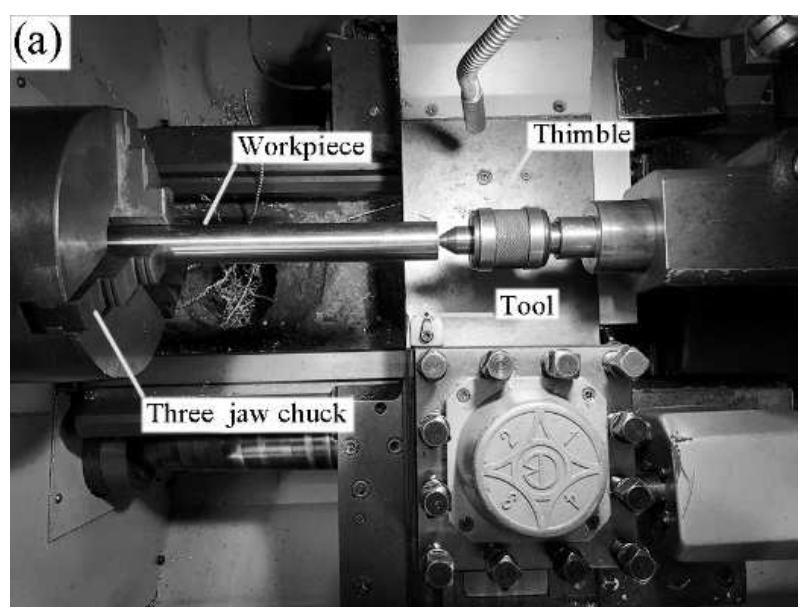

a) Cutting device

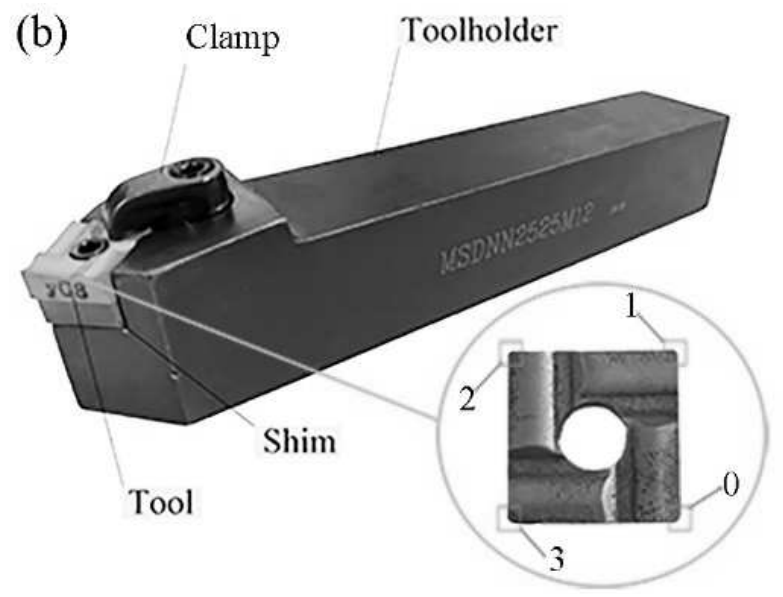

b) Tool components

Fig. 1 Cutting device and tool

\section{Experimental results and discussion}

\subsection{Cutting force and cutting heat of tool}

During the cutting process, the cutting force is generated by the elastic-plastic deformation resistance and the friction force between material and tool. It can be decomposed into three branches along three direction, namely the main cutting force $F_{c}$, the feed force $F_{t}$ and the back force $F_{p}$, as shown in Fig. 2(a). In the cutting process, the workpiece material is deformed elastically by the action of the tool extrusion. The metal material that has been plastically deformed is separated from the workpiece and slips along the shear plane to form chips. They flow along the rake face of the tool and generate a large amount of cutting heat. At the same time, the metal cutting layer is plastically deformed by the extrusion and friction of the tool edge which leads to generating a lot of cutting heat.

According to the cutting temperature theory of Shaw MC. It is assumed that the heat generated in the shear zone, the contact zone between the rake face and the chips bottom, the contact zone between the flank face and the machined surface are all transferred to cutting heat [16]. The transferred paths of the tool cutting heat are shown in Fig. 2(b), and the cutting heat transfers to the chips, workpiece and the tool respectively. It leads to the increase of the workpiece temperature, and high cutting temperature burns the workpiece material, then the surface quality of the workpiece declines. Meanwhile the heat transferred to the tool can result in chemical reaction between the elements in the tool and the elements in the air, which reduces the hardness of the tool and shortens its service life.

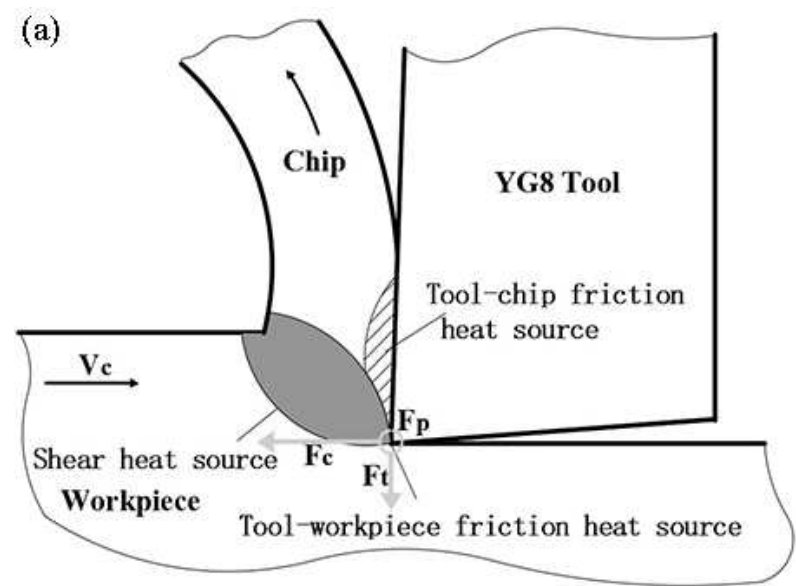

a) Sketch of cutting area's beat

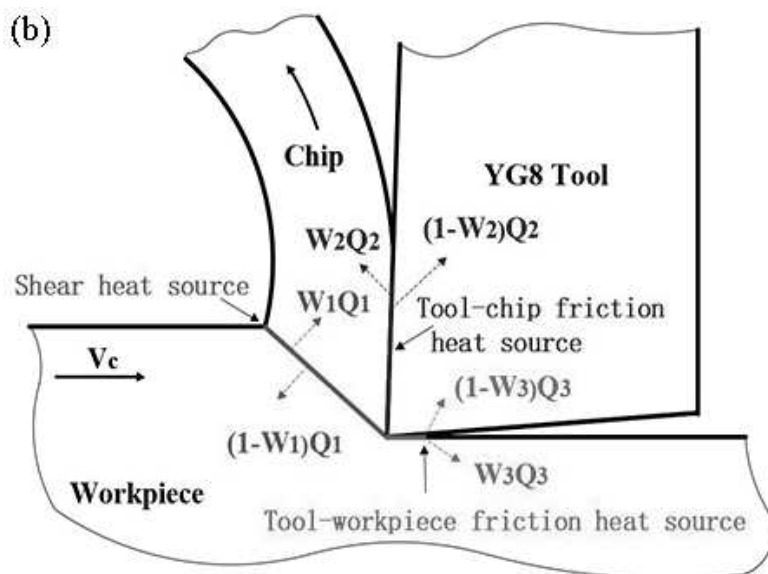

b) Sketch of cutting area's heat transfer

Fig. 2 Sketch of cutting heat and heat transfer

\subsection{Before cutting}

Scanning electron microscope (SEM) was applied to observe the cutting edge of No.0 tool nose, and the surface morphology of the rake and flank faces are shown in Fig.3(a)-(c), respectively. The energy spectrum of element distribution at point $A$ marked on the rake face is displayed in Fig.3(d). It can be seen from Fig.3(a)-(c) that the cutting edge is complete, and the tool nose is sharp. Energy spectrum diagram of Fig.3(d) illustrates that the tool material contains $6.34 \%$ C, $6.89 \%$ Co and $86.77 \%$ W. It can be seen that there are still three types of elements distributed in the 
tool which are compared with those in Table. 3, so there are not any other impurity elements in the tool. Co is used as the adhesive for cemented carbide tool, which acounts for $8 \%$ of total mass score, while the measured content of $\mathrm{Co}$ at point $\mathrm{A}$ is $6.89 \%$. This difference attributes to the uneven composition of the structure in the tool material.

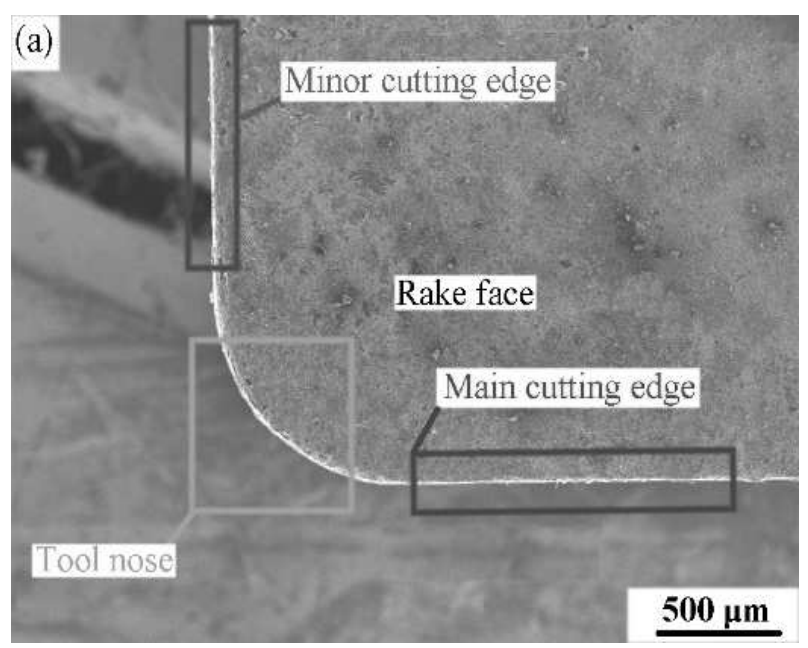

a) SEM morphology of rake face

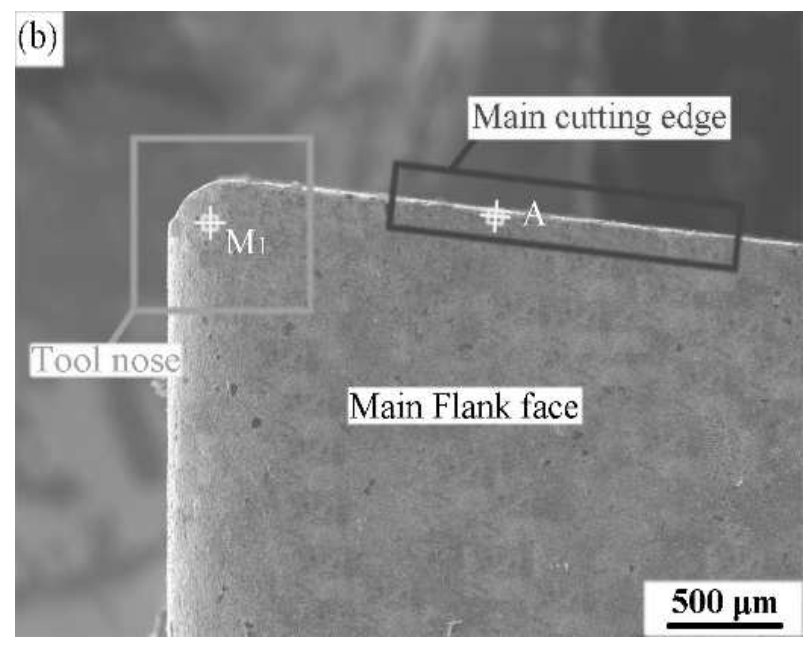

b) SEM morphology of main flank face

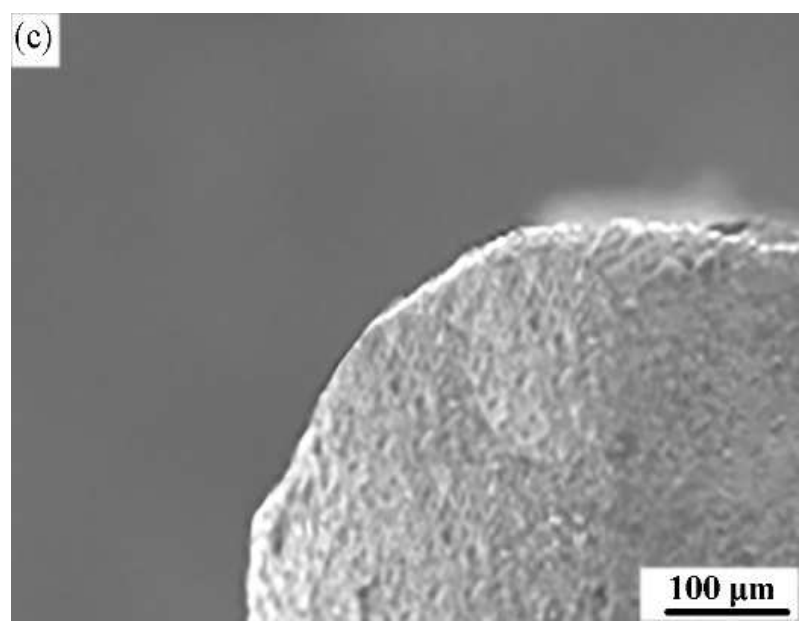

c) Enlargement of area $M_{1}$ (d) Full scale counts: $1412 \quad$ New Project(62)_pt1

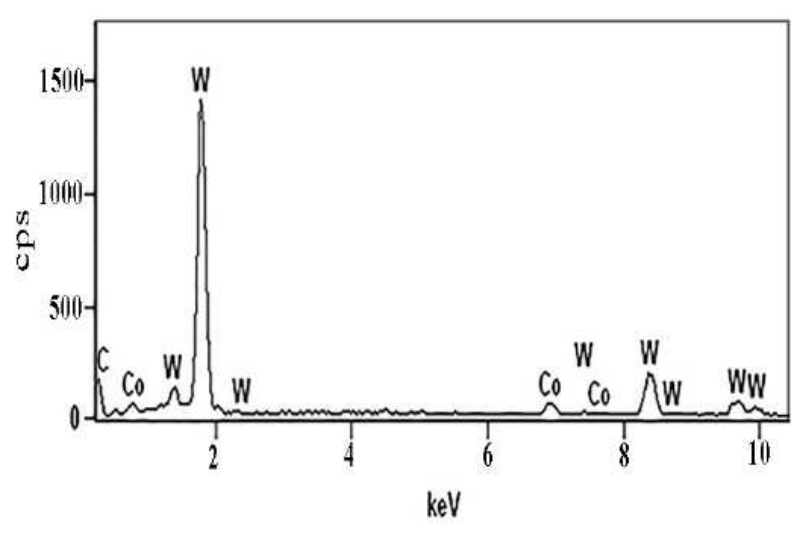

d) SEM energy spectrum of point $A$

Fig. 3 Morphology of the workpiece and tool surface and energy spectrum of tool

\subsection{The initial stage of the cutting}

The cutting edge of the tool at initial stage of cutting corresponds to the No.1 in Fig. 1(b). After cutting for 6 minutes, the morphology diagrams of the tool nose are shown in Fig. 4(a)-(c). The energy spectrum of element distribution at point $\mathrm{B}$ marked on the rake face is illustrated in Fig. 4(b). From Fig. 4(a)-(b), it can be seen that there is slight wear at tool nose, which is due to the constant contact friction between the workpiece and the tool surface. Some micro-cracks on the tool surface are generated by the action of constant mechanical stress, which leads to the shedding of the tool material. Some researches revealed that stress concentration can lead to cracks on the surface of tool, and compressive residual stress can effectively inhibit the initiation and development of fatigue crack on the surface of tool and prolong its service life [17-18], such as shot peening[19], laser peening[20-21]. As Fig. 4(c) illustrated, there are some small pits on the rake face of the tool and some tiny scratches near the main cutting edge. Fig. 4(d) displays the material at point B contains $4.26 \% \mathrm{C}, 5.72 \% \mathrm{Co}$, $70.11 \% \mathrm{~W}, 11.48 \% \mathrm{Fe}, 6.12 \% \mathrm{Cr}$ and $2.31 \% \mathrm{Ni}$. Compared with the element contents of $\mathrm{C}, \mathrm{Co}, \mathrm{W}$ shown in Fig. 3(d), the corresponding values of these elements in rake face of tool are decreased obviously. The elements of $\mathrm{Fe}, \mathrm{Ni}$, Co belong to one family and have strong chemical affinity, which leads to the loss of Co in cemented carbide tool. As a result, the bonding strength of WC particles is decreased, and WC particles is easily worn off from the tool, and the hardness of the tool is reduced. Meanwhile, the tiny particles in the tool material adhere to the chips and workpiece, and they are taken away by the chips during the cutting process. Then some tiny pits are produced by the loss of its material, which is called adhesion wear. Sometimes the hard particles existed in the workpiece material plow the tool surface continuously, 
which leaves tiny scratches on it easily. This kind of wear is abrasive wear, a common type of tool wear. Fig. 4(e) demonstrates three-dimension morphology of the workpiece. Fig.4(f) shows the surface profile is measured along the defined path with Gwyddion software. It can be seen that the surface roughness $\mathrm{Ra}$ of the workpiece is $1.4 \mu \mathrm{m}$. Therefore, the quality of the workpiece surface is good.

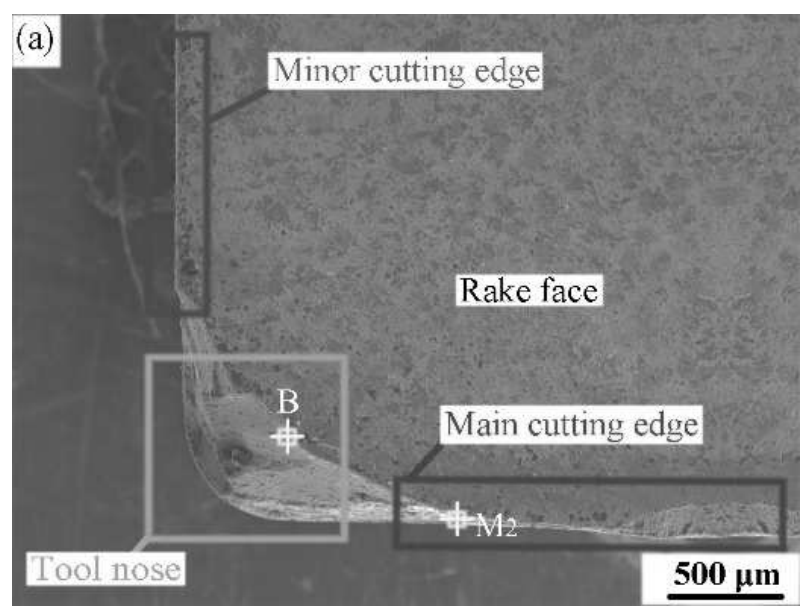

a) SEM morphology of rake face

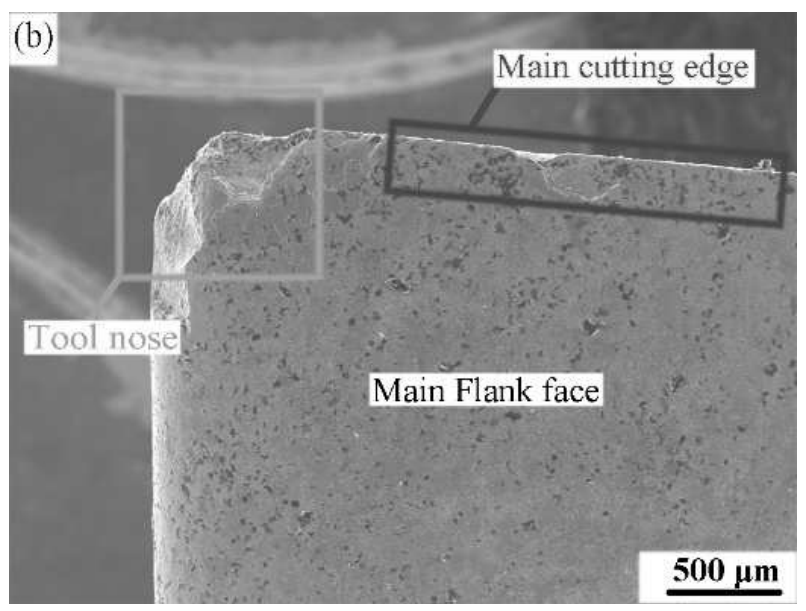

b) SEM morphology of main flank face

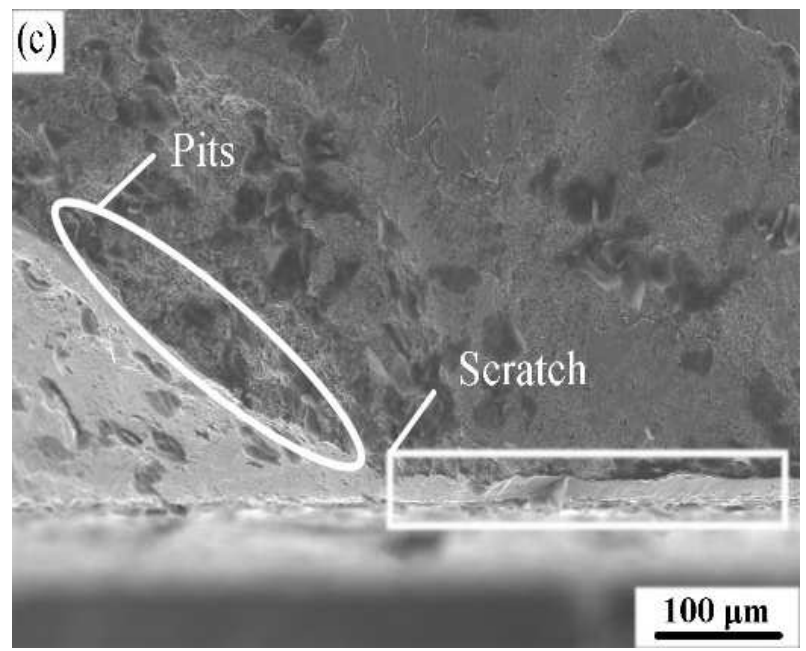

c) Enlargement of area $M_{2}$ (d) Full scale counts: 1976 New Project(50)_pt1

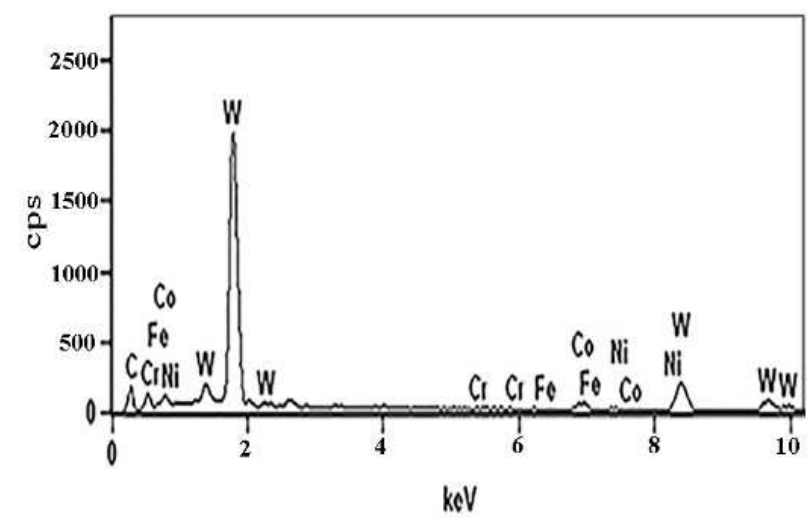

d) SEM energy spectrum of point $B$

(e)

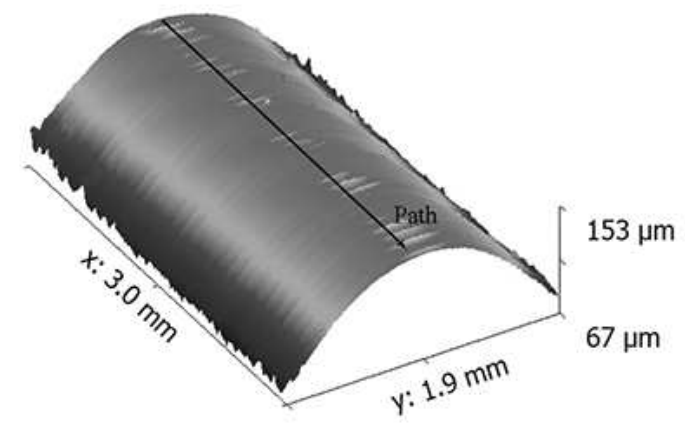

e) 3D microscopic profile of workpiece surface

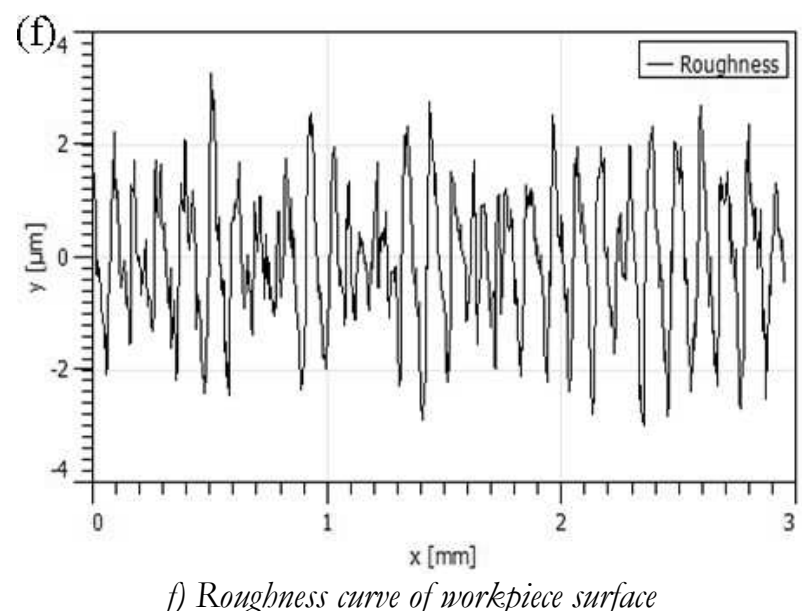

Fig. 4 Morphology of the workpiece and tool surface and energy spectrum of tool (cutting time of 6 minutes)

\subsection{The middle stage of cutting}

The cutting edge of the tool in the middle cutting stage corresponds to the No. 2 tool nose in Fig. 1(b). After 12 minutes of cutting, the morphology of the No. 2 tool nose is shown in Fig. 5(a)-(c). The energy spectrum of the elements distribution at point $\mathrm{C}$ marked on rake face is exhibited in Fig. 5(d). As displayed in Fig. 5(a)-(c), the wear volume at the tool nose is increased, and the edge wear is more serious after 
12 minutes of cutting in comparison with that after 6 minutes of cutting. According to Fig. 2(b), a large amount of cutting heat is transferred to the workpiece during the cutting process, the cutting heat is accumulated continuously with the cutting time extension. As we known, the thermal conductivity of 304 stainless steel is $16.3 \mathrm{~W} /(\mathrm{m} \cdot \mathrm{K})$, while the coefficient of heat conduction of Q235 steel is currently $49.7 \mathrm{~W} /(\mathrm{m} \cdot \mathrm{K})$. Therefore, the thermal conductance of 304 stainless steel is poorer, and the heat in the cutting zone is difficult to conduct out in time. As a result, cutting temperature is increased, which softens the tool material and accelerates the wear of the tool nose. As illustrated in Fig. $5(\mathrm{~d})$, the material of point $\mathrm{C}$ contains $1.82 \% \mathrm{C}$, $4.31 \% \mathrm{Co}, 57.52 \% \mathrm{~W}, 23.17 \% \mathrm{Fe}, 5.26 \% \mathrm{Ni}, 5.84 \%$ $\mathrm{Cr}$, and $2.08 \% \mathrm{O}$. Compared with the elements contents of 6 minutes cutting, the contents of $\mathrm{Fe}, \mathrm{Ni}$ and $\mathrm{Cr}$ on the tool are increased, while the contents of $\mathrm{C}$, $\mathrm{Co}, \mathrm{W}$ are decreased slightly. The main reason for this phenomenon is that the elevation of cutting temperature results in the aggravation of adhesive wear with the extension of cutting time. It leads to the adhesion of some stainless steel material to the tool surface. However, the reason for the existence of element $\mathrm{O}$ in the tool is that the material of cutting tool is easily oxidized in the air at the high cutting temperature [22]. The chemical formula (1) and formula (2) are as follows:

$$
\begin{gathered}
2 \mathrm{WC}+5 \mathrm{O}_{2}=2 \mathrm{WO}_{3}+2 \mathrm{CO}_{2} \\
\mathrm{WC}+2 \mathrm{O}_{2}=\mathrm{WO}_{2}+\mathrm{CO}_{2}
\end{gathered}
$$

$\mathrm{WO}_{2}$ and $\mathrm{WO}_{3}$, the products of oxidized reaction, are increased with the reduction of WC. As a result, the cutting performance of the tool is deteriorated. Moreover, these oxides remain on the tool surface, and it is susceptible to be damaged by the friction between workpiece and chips which is due to its low hardness. When the surface oxides are worn out, the newer come into being. WC is reoxidized and rubbed off repetitively, which results in the oxidation wear of the tool.

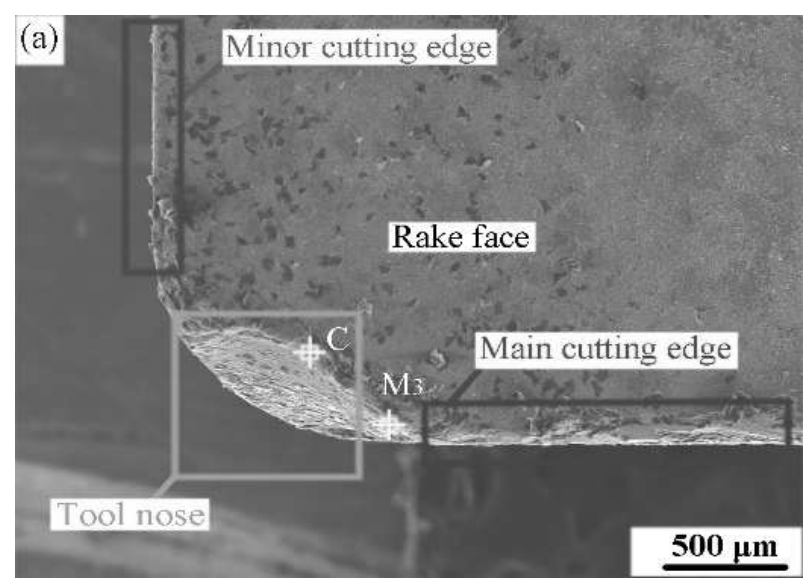

a) SEM morphology of rake face

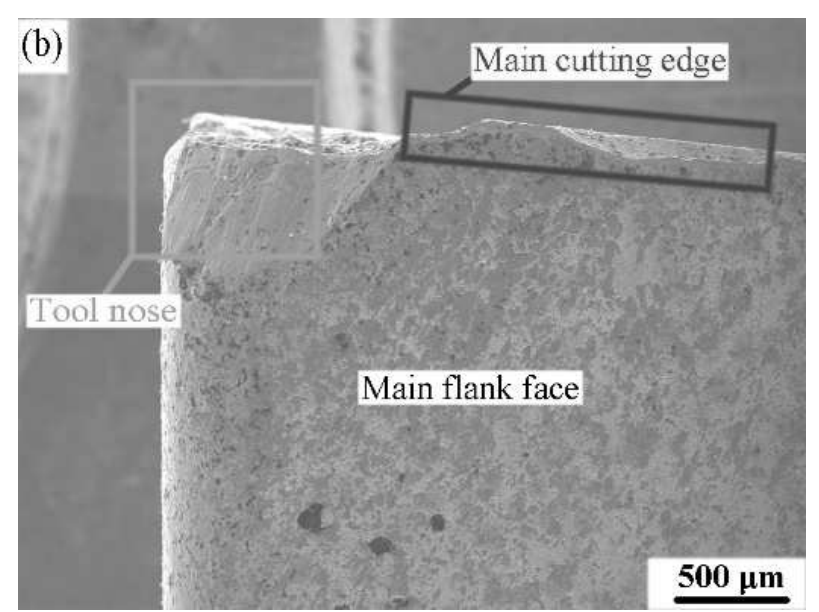

b) SEM morphology of main flank face

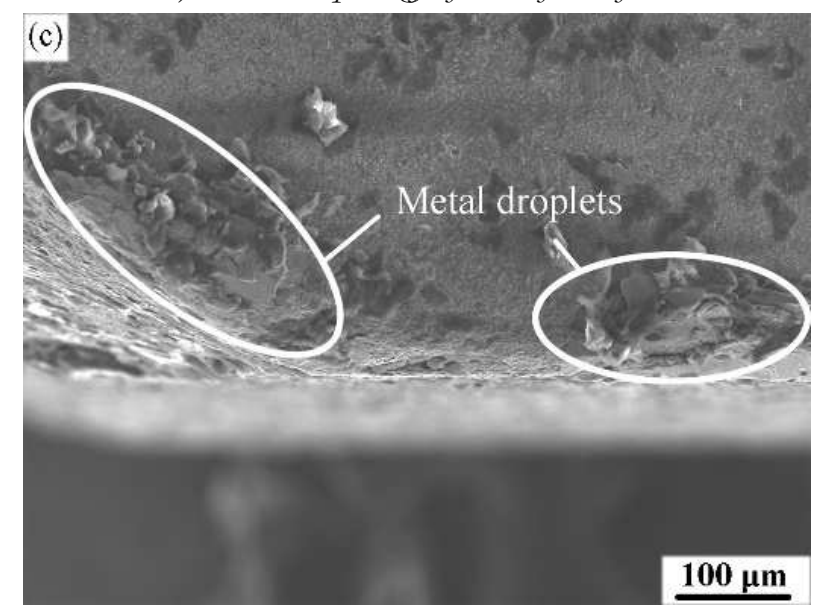

c) Enlargement of area $M_{3}$

(d) Full scale counts: 1107 New Project(58)_pt1

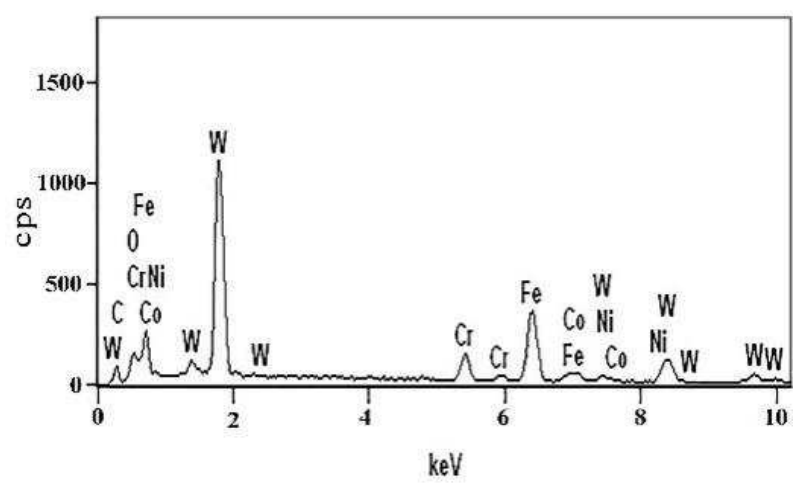

d) SEM energy spectrum of point $C$

(e)

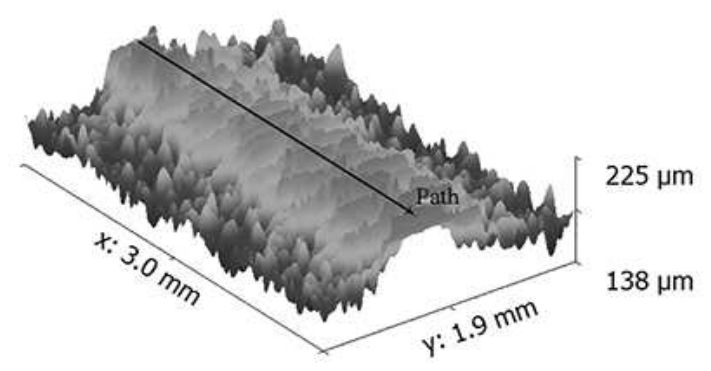

e) 3D microscopic profile of workpiece surface 


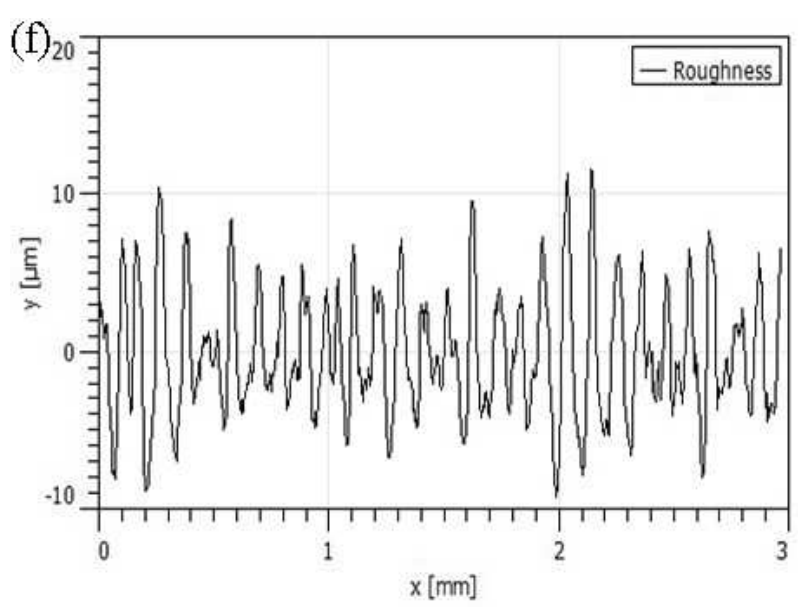

f) Roughness curve of workpiece surface

Fig. 5 Morphology of the workpiece and tool surface and energy spectrum of tool (cutting time of 12 minutes)

Fig. 5(e) shows the three-dimensional micro-topography of workpiece, and there are many tiny grooves on the surface of workpiece. Fig. 5(f) displays the surface contour of the workpiece, and the surface roughness $\mathrm{Ra}$ of workpiece is $10.3 \mu \mathrm{m}$. Obviously, it is much larger than that resulted from cutting for $6 \mathrm{mi}$ nutes, and the surface quality is worse further.

\subsection{The final stage of cutting}

The cutting edge in the final cutting stage corresponds to the No. 3 tool nose in Fig. 1(b). Fig. 6(a)-(c) exhibit the morphology of the No. 3 tool nose after 18 minutes of cutting. Fig. 6(d) displays the energy spectrum of the elements distribution at point $D$ marked on rake face. From Fig.6(a)-(c), it can be seen the wear of the tool nose is heavy, and the wear volume of the main cutting edge is further increased. According to Fig. 6(d), the material of point D contains $1.93 \%$ C, $9.87 \%$ Co, $8.79 \%$ W, 48.59\% Fe, $8.14 \% \mathrm{Ni}$, $17.84 \% \mathrm{Cr}, 4.84 \%$ O. Compared with the energy spectrum of cutting tool which is subjected to cutting for 12 minutes, the contents of $\mathrm{Fe}, \mathrm{Ni}, \mathrm{Cr}$, O in the rake face have been increased, which indicates that the rake face is covered with some stainless steel materials and oxides.So the oxidation wear and adhesive wear are seriously deteriorated on the tool surface. The reasons are ascribed to the following: with the increasing of cutting resistance induced by tool gradual passivation, the cutting temperature rises constantly, which speeds up the oxidation reaction between metal and oxygen and makes the oxidation film and adhesion film cover the tool surface. The high temperature also accelerates the loss of element Co in the tool, which changes the material's composition ratio and reduces the mechanical property of the tool [23]. Fig. 6(e)-(f) display the three-dimensional micro-topography and surface contour diagram of the workpiece, respectively. As illustrated in Fig. 6(e), there are tiny grooves appeared on the workpiece surface. The surface roughness $\mathrm{Ra}$ of the workpiece is increased to $19.4 \mu \mathrm{m}$, which is larger than the value of workpiece that is subjected to cutting with shorter time. The surface of workpiece is extremly rough and the quality is poor, so that the cutting tool can't meet the requirements of finish machining.

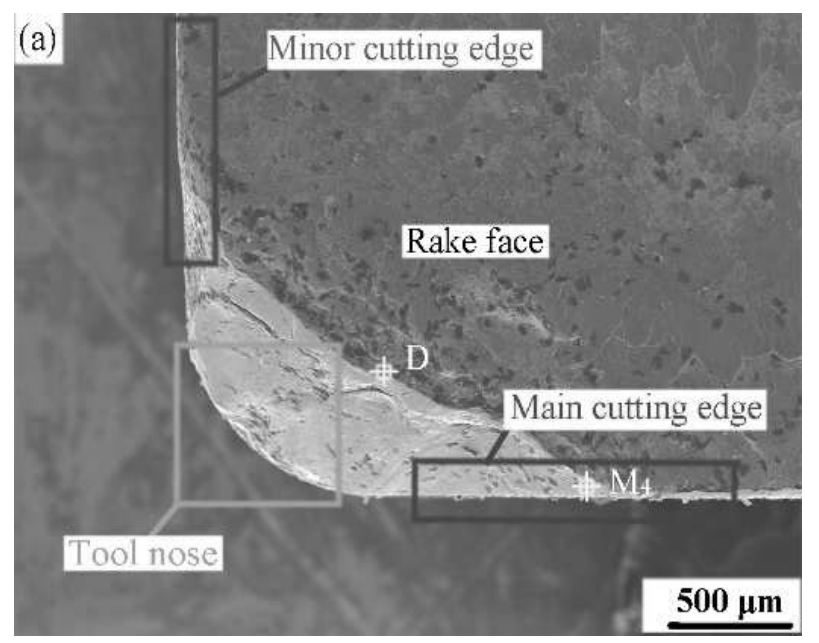

a) SEM morphology of rake face

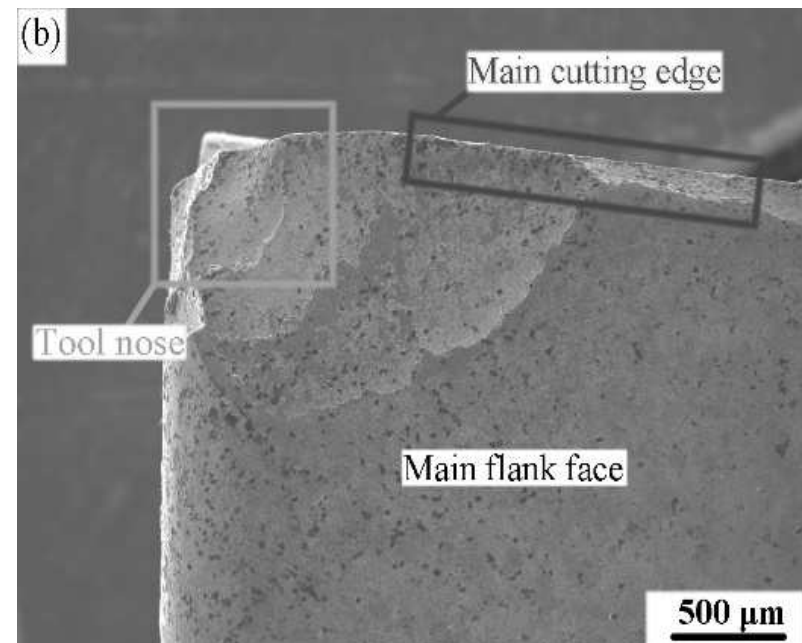

b) SEM morphology of main flank face

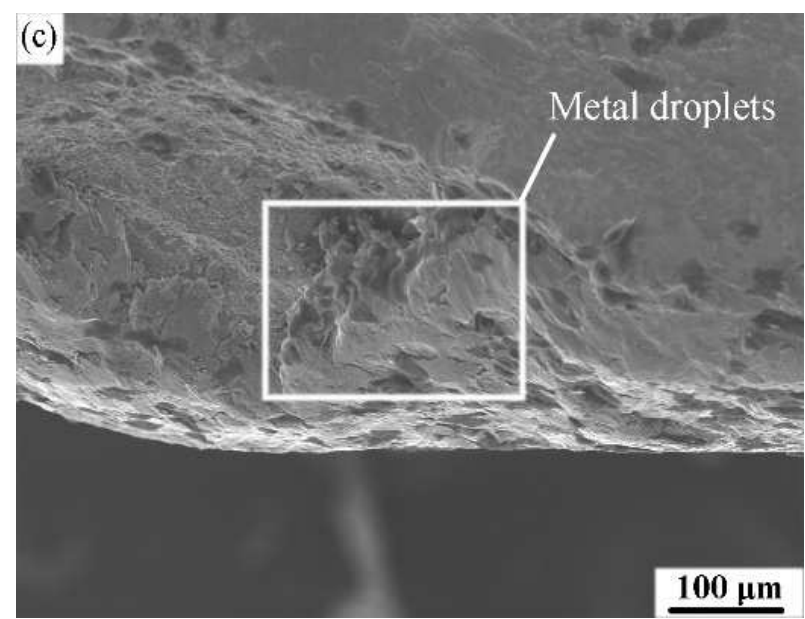

c) Enlargement of area $M_{4}$ 
(d) Full scale counts: 742 New Project(58)_pt1

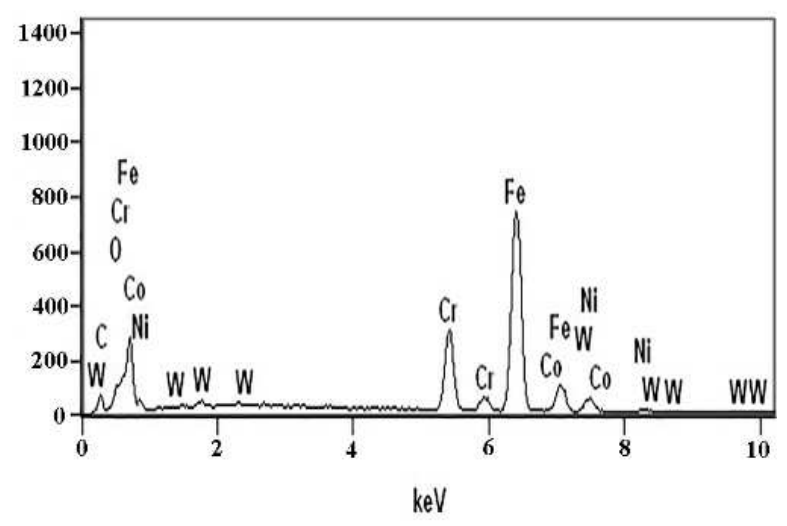

d) SEM energy spectrum of point D

(e)

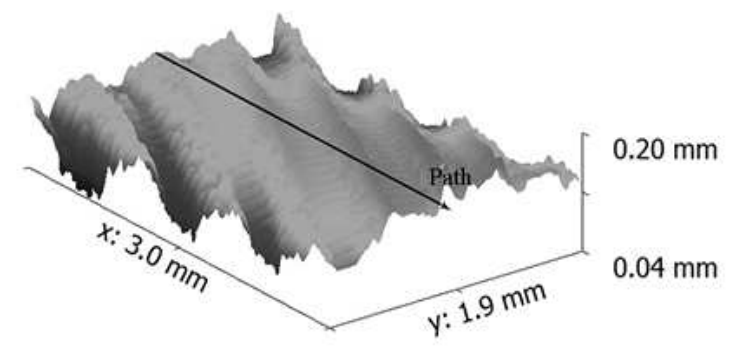

e) 3D microscopic profile of workpiece surface

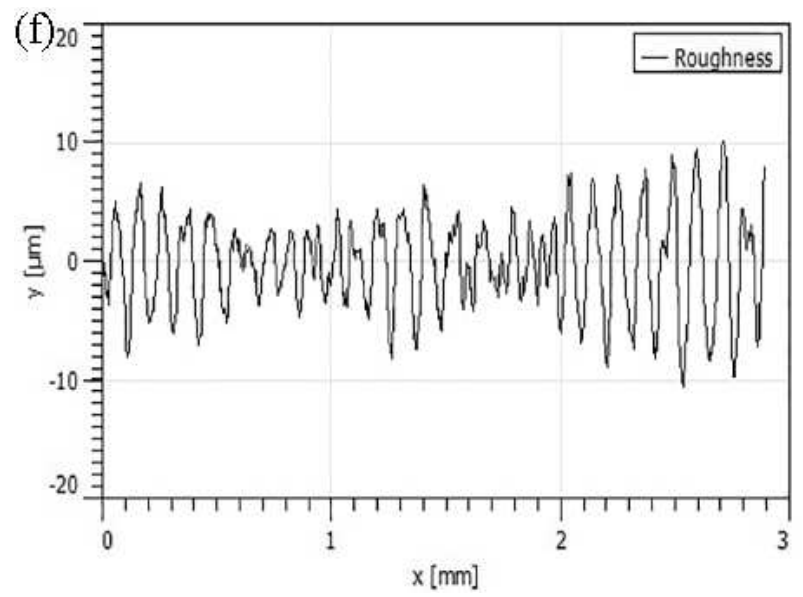

f) Roughness curve of workpiece surface

Fig. 6 Morphology of the workpiece and tool surface and energy spectrum of tool (cutting time of 18 minutes)

\section{Conclusion}

YG8 cemented carbide tool has been widely used in many kinds of cutting with cooling lubricant, but it has been seldom reported that was utilized in dry cutting, so this research has a certain practical value. After the experiment of different cutting times, the tool was evaluated by the scanning electron microscope JSM-6490LV and EDS analyzer which was part of this microscope. And the three-dimensional morphology of the workpiece surface was obtained by RETC-UP 3D topography instrument. From the above images, the authors formulated the following conclusions:

I. Under the condition of cutting speed 80 $\mathrm{m} / \mathrm{min}$, cutting depth $0.6 \mathrm{~mm}$ and feed rate $0.12 \mathrm{~mm} / \mathrm{r}$, the wear volume of cemented carbide tool increases with the extension of cutting time. The wear volume of main cutting edge is larger than that of minor cutting edge.

II. The wear mechanism of the tool subjectes to a short time cutting is abrasive wear and adhesive wear. Experiencing a long time cutting, the types of tool wear mainly belong to abrasive wear, adhesive wear and oxidation wear.

III. With the raising of wear volume, the contact area between workpiece and tool is enlarged. the surface roughness $\mathrm{Ra}$ of the workpiece increases from $1.4 \mu \mathrm{m}$ to $19.4 \mu \mathrm{m}$, so the quality of the workpiece surface decreases obviously.

Through the analysis of tool wear in different cutting time, the mechanism of tool wear is mastered. It can help to solve the problem about tool wear in the process of high-speed cutting aviation stainless steel with cemented carbide tools, and reduce the cost of tools and improve the machining quality of workpieces.

\section{Acknowledgement}

The authors express their thanks for the financial support to the Key Research and Development Projects in Anhui (201904a05020065), National Natural Science Foundation of Anhui province (No. 1708085ME110).

\section{References}

[1] AKKURT, A. (2009). Surface properties of the cut face obtained by different cutting methods from AISI 304 stainless steel materials. In: Indian Journal of Engineering and Materials Sciences, Vol. 16, No. 6, pp. 373-384.

[2] TEKASLAN, O., GERGER, N., SEKER, U. (2009). A study on residual stresses formed on AISI 304 austenitic stainless steels when machined with different cutting parameters. In: Journal of the Faculty of Engineering and Architecture of Gari University, Vol. 24, No. 3, pp. 443-452.

[3] JANAINA, G. C., ROLF, B. S., ÁLISSON, R. M. (2017). Tool life and wear mechanism analysis of carbide tools used in the machining of 
martensitic and supermartensitic stainless steels. In: Tribology International, Vol.105, pp. 102117.

[4] KROLCZYK, G. M., NIESLONY, P., LEGUTKO, S. (2015). Determination of tool life and research wear during duplex stainless steel turning. In: Archives of Civil and Mechanical Engineering, Vol. 15, No. 2, pp. 347-354.

[5] KROLCZYK, G. M., MARUDA, R. W., KROLCZYK, J. B. et al. (2018). Parametric and nonparametric description of the surface topography in the dry and MQCL cutting conditions. In: Measurement, Vol.121, pp. 225-239.

[6] KROLCZYK, G., GAJEK, M., LEGUTKO, S. (2013). Effect of the cutting parameters impact on tool life in duplex stainless steel turning process. In: Tehnicki Vjesnik-Technical Gazette, Vol. 20, No. 4, pp. 587-592.

[7] JOHANNES, K., DANIEL, B., JENS, G. et al. (2015). Study on micro texturing of uncoated cemented carbide cutting tools for wear improvement and built-up edge stabilisation. In: Journal of Materials Processing Technology, Vol. 215, No. 1, pp. 62-70.

[8] KOLAR, P., SULITKA, M., FOJTU, P., et al. (2016). Cutting force modelling with a combined influence of tool wear and tool geometry. In: Manufacturing Technology, Vol. 16, No. 3, pp. 524-531.

[9] ROSA, G. C., SOUZA, A. J., POSSAMAI, E. $\mathrm{V}$. et al. (2017). Wear analysis of ultra-fine grain coated carbide tools in hard turning of AISI 420C stainless steel. In: Wear, Vol. 376-377, pp.172-177.

[10] SAKETI, S., BEXELL, U., OSTBY, J. et al. (2018). Wear behaviour of two different cemented carbide grades in turning $316 \mathrm{~L}$ stainless steel. In: Materials Science Forum, Vol. 941, pp.2367-2372.

[11] NESLUSAN, M., CILLIKOVA, M., MICIETOVA, A. et al. (2018). Influence of tool wear on surface after turning stainless steels. In: Manufacturing Technology, Vol. 18, No. 5, pp. 793-798.

[12] LIU, Z. Q., CHEN, M., AN, Q. L. (2015). Investigation of friction in end-milling of Ti-6Al$4 \mathrm{~V}$ under different green cutting conditions. In: International Journal of Advanced Manufacturing Technology, Vol. 78, No. 5-8, pp. 1181-1192.

[13] ANSELMO, E. D., RICARDO, M. (2002). Cutting conditions for finish turning process aiming: the use of dry cutting. In: International
Journal of Machine Tools \& Manufacture, Vol. 42, No. 8, pp. 899-904.

[14] KROLCZYK, G. M., LEGUTKO, S. (2014). Experimental analysis by measurement of surface roughness variations in turning process of duplex stainless steel. In: Metrology and Measurement Systems, Vol. 21, No. 4, pp. 759-770.

[15] PATHIRANAGAMA, G. J., NAMAZI, H. (2019). Fractal based analysis of the effect of machining parameters on surface finish of workpiece in turning operation. In: Fractals, Vol. 2.

[16] SHAW, M. C., VYAS, A. (1998). The mechanism of chip formation with hard turning steel. In: Cirp Annals - Manufacturing Technology, Vol. 47, No. 1, pp. 77-82.

[17] ZHANG, X. Q., LI, H., YU, X. L. et al. (2015). Investigation on effect of laser shock processing on fatigue crack initiation and its growth in aluminum alloy plate. In: Materials and Design, Vol. 65, pp. 425-431.

[18] ZHANG, X. Q., CHEN, L. S., LI, S. Z. et al. (2015). Investigation of the fatigue life of preand post-drilling hole in dog-bone specimen subjected to laser shot peening, In: Materials and Design, Vol. 88, pp 106-114.

[19] TRUNG, P. Q., KHUN, N. W., BUTLER, D. L. (2018). Effect of shot peening process on the fatigue life of shot peened low alloy steel. In: Journal of Engineering Materials and Technology, Vol. 140, No. 1.

[20] ZHANG, X., LI, H, DUAN, S.W. et al. (2019). Modeling of residual stress field induced in Ti6Al-4V alloy plate by two sided laser shock processing. In: Surface and Coatings Technology, Vol. 280, pp.163-173.

[21] ZHANG, X. Q., HUANG, Z. W., CHEN, B. et al. (2019). Investigation on residual stress distribution in thin plate subjected to two sided laser shock processing. In: Optics \& Laser Technology, Vol.111, pp:146-155.

[22] BABAK, S., POPOV, A. (2017). The effect of the tool wear on the correlation of forces on the face and flank surfaces of the cutting tool. In: Manufacturing Technology, Vol. 17, No.3, pp. 283287.

[23] BOSIO, F., BASSONI, E., ONATE, S. et al. (2018). The influence of microstructure on abrasive wear resistance of selected cemented carbide grades operating as cutting tools in dry and foam conditioned soil. In: Wear, Vol. 394395, pp. 203-216. 